\title{
Poverty and economic decision making: a review of scarcity theory
}

\author{
Ernst-Jan de Bruijn $^{1,2}$ (D) Gerrit Antonides ${ }^{1}$ (D)
}

Accepted: 8 February 2021 / Published online: 9 March 2021

(C) The Author(s) 2021

\begin{abstract}
Poverty is associated with a wide range of counterproductive economic behaviors. Scarcity theory proposes that poverty itself induces a scarcity mindset, which subsequently forces the poor into suboptimal decisions and behaviors. The purpose of our work is to provide an integrated, up-to-date, critical review of this theory. To this end, we reviewed the empirical evidence for three fundamental propositions: (1) Poverty leads to attentional focus and neglect causing overborrowing, (2) poverty induces trade-off thinking resulting in more consistent consumption decisions, and (3) poverty reduces mental bandwidth and subsequently increases time discounting and risk aversion. Our findings indicate that the current literature predominantly confirms the first and second proposition, although methodological issues prevent a firm conclusion. Evidence for the third proposition was not conclusive. Additionally, we evaluated the overall status of scarcity theory. Although the theory provides an original, coherent, and parsimonious explanation for the relationship between financial scarcity and economic decision making, the theory does not fully accord with the data and lacks some precision. We conclude that both theoretical and empirical work are needed to build a stronger theory.
\end{abstract}

Keywords Scarcity theory $\cdot$ Literature review $\cdot$ Poverty $\cdot$ Cognition · Attention · Economic decision making

Ernst-Jan de Bruijn

Ernst-Jan.deBruijn@wur.nl

1 Department of Social Sciences, Wageningen University, P.O. Box 8130,

6700 EW Wageningen, The Netherlands

2 Department of Economics, Leiden University, Leiden, The Netherlands 


\section{Introduction}

Poverty is associated with seemingly irrational and counterproductive behaviors in several areas of economic life, both in developed and developing countries. Lowincome households tend to save too little (Shurtleff 2009), to borrow repeatedly at high-interest rates (Banerjee and Duflo 2007; Skiba and Tobacman 2008), and to spend relatively large parts of money on tobacco, alcohol, and lotteries (Banerjee and Duflo 2007; Blalock et al. 2007; Haisley et al. 2008; World Health Organization 2011). Additionally, low-income individuals are more likely to cut back their nonemergency healthcare services (Lusardi et al. 2010) and while they are eligible for welfare programs, take-up rates are low (Bertrand et al. 2006; Hernanz et al. 2004). The debate about these behaviors of the poor reflects several views. One view suggests that these behaviors mirror the poor's preferences and should be seen as rational adaptations to their economic circumstances. The culture-of-poverty view proposes that the poor's norms, values, and attitudes deviate from others and shape their preferences and behaviors (Lewis 1998). The human capital view suggests that these behaviors reflect a lack of human capital due to a lack of education, work experience, and financial literacy (see e.g., Lusardi and Mitchell 2014).

A few years ago, Mullainathan and Shafir (2013) published their influential book, Scarcity, presenting a new theory about these behaviors. ${ }^{12}$ Scarcity theory integrates insights from cognitive psychology and economics and attempts to explain a wide range of behaviors of the poor. The poor have to make their decisions under severe financial conditions that change the way they feel and think. Mullainathan and Shafir (2013) propose that poverty itself induces a scarcity mindset, which subsequently affects the poor's decisions and behaviors. The poor face tight budgets and income volatility, which requires them to juggle with current and upcoming expenditures. These urgent demands consume elementary cognitive resources, such as attention, executive control, and working memory, leaving fewer resources for non-pressing demands. As a consequence, financial scarcity forces the poor into counterproductive behaviors that may perpetuate the condition of poverty.

Scarcity theory is widely seen as a unified, attractive, and promising view on poverty and economic decision making. ${ }^{3}$ This theory played a prominent role in the World Development Report 2015 (2015). Furthermore, this theory has opened a new direction for scientific research. Scientists from different disciplines have begun to test specific elements of scarcity theory in lab studies and real-world settings (e.g., Carvalho et al. 2016; Fehr et al. 2019; Huijsmans et al. 2019; Lichand and Mani

\footnotetext{
${ }^{1}$ Scarcity theory is part of the behavioral economic view proposing that the behaviors of the poor reflect a psychology of poverty. Living in poverty creates specific psychological outcomes (e.g., stress, negative affect, mental bandwidth tax) that subsequently impair economic decision making (see e.g., Haushofer and Fehr 2014; Schilbach et al. 2016).

2 The book received positive reviews from Nobel Prize winners Daniel Kahneman and Richard Thaler, several other leading behavioral economic experts, and popular media. According to The Economist, "the book's unified theory of the scarcity mentality is novel in its scope and ambition" (The Economist 2013).

3 Mullainathan and Shafir did not provide a single umbrella term for the theory discussed in their book. Others refer to the theory as "psychological responses to scarcity" (Zhao and Tomm 2018) or "resource scarcity" (Hamilton et al. 2019a, b). We will consistently use the term "scarcity theory," referring to the title of their book.
} 
2020; Ong et al. 2019; Plantinga et al. 2018; Shah et al. 2015). Other studies integrated elements of the theory into broader frameworks explaining consumption behavior and economic decision making under financial constraints (Adamkovič and Martončik 2017; Cannon et al. 2019; Hamilton et al. 2019a, b; Hamilton, Thompson, et al. 2019a, b).

The purpose of our work is to provide an integrated review of scarcity theory applied to the context of poverty. To this end, we focus on reviewing the evidence for three fundamental propositions of this theory. First, poverty leads to an attentional focus on scarcity-related demands and neglect of other issues, causing overborrowing. Second, poverty induces trade-off thinking, i.e. weighing a particular expense against other possible expenses, resulting in more consistent consumption decisions. Third, poverty reduces mental bandwidth (cognitive capacity and cognitive control), increasing time discounting and risk aversion. For each of these propositions, we discuss its foundation and review initial and new studies, including replications, non-findings, and criticisms. Additionally, we discuss the implications for the validity and generalizability of the proposition, identify gaps in knowledge, and propose pathways for future research. Finally, we integrate our findings into an overall evaluation of the status of scarcity theory.

Our study results in four main findings. First, lab studies provide consistent evidence of scarcity drawing one's attentional focus to scarcity-related demands and causing overborrowing. However, the literature lacks field studies investigating whether these mechanisms hold in real-world contexts. Second, most studies confirm that poverty induces trade-off thinking and subsequently results in more consistent consumption decisions, but important methodological issues prevent a firm conclusion. Third, the literature provides mixed evidence of poverty impairing cognitive capacity and cognitive control, and only weak evidence of poverty increasing time discounting and risk aversion via this mechanism. Fourth, although scarcity theory does provide an original, coherent, and parsimonious explanation that financial scarcity affects economic decision making, the theory does not fully accord with the data. We conclude that both theoretical and empirical work is needed to address this issue.

Our work contributes to the current literature by providing an up-to-date and integrative overview of the literature and by critically reviewing the evidence of scarcity theory applied to poverty and economic decision making. Previous literature studies have concentrated on providing an overview of the key ideas of scarcity theory and evidence supporting this theory (Shah et al. 2015; Zhao and Tomm 2018). Others discussed evidence for specific relationships of the theory as part of a broader literature review (Adamkovič and Martončik 2017; Cannon et al. 2019; Dean et al. 2019; Hamilton et al. 2019a, b; Kremer et al. 2019; SheehySkeffington and Rea 2017). While the field is fast-growing, the literature lacks an up-to-date, integrative, and critical review of (the evidence for) all key aspects of scarcity theory. ${ }^{4}$ Our work aims at filling this gap.

\footnotetext{
4 Almost half of the reviewed studies appeared in 2019 or 2020. Most of these studies were not included in previous reviews.
} 
Our paper proceeds as follows. In Sect. 2, we discuss the main concepts of scarcity theory and methods used in empirical studies. Sections 3-5 review the literature concerning the three key propositions of scarcity theory mentioned above. In Sect. 6, we discuss our integrated findings and general directions for future research.

\section{Scarcity theory: an overview}

Scarcity theory explains several behaviors and decisions of people who face scarcity in a particular area of life. Mullainathan and Shafir (2013) define scarcity as "having less than you feel you need" (p. 4). ${ }^{5}$ Scarcity can be experienced in several contexts, e.g., when people are dieting, when being thirsty, by facing deadlines, in the case of loneliness, and when facing poverty (Cannon et al. 2019). The theory builds on cognitive psychological research regarding several features of human cognition that affect (economic) decision making. The key idea of scarcity theory is that scarcity itself induces a specific mindset by affecting how people think and decide, and subsequently affect human behaviors. Poverty is the key domain to which scarcity theory has been applied (Zhao and Tomm 2018).

Figure 1 reflects the theoretical framework of scarcity theory applied to poverty and economic decision making. ${ }^{6}$ In this framework, poverty affects economic decisions and behaviors via three routes stemming from two core psychological mechanisms (tunneling and cognitive load). ${ }^{7}$ First, poverty causes an attentional focus that enhances resource efficiency and facilitates memory-encoding, and an attentional neglect that leads to forgetful, neglectful, and overborrowing behaviors (arrows 1 and 2). This process of attentional focus and neglect is also referred to as tunneling. Second, poverty-induced focus causes trade-off thinking (3) which creates a more stable frame of value and consistent consumption decisions (4). Third, poverty reduces mental bandwidth (cognitive capacity and executive control) (5) and subsequently increases temporal discounting and risk aversion (6). Scarcity theory assumes that cognitive load underlies the negative effect of poverty on cognitive capacity and executive control.

As reflected in Fig. 1, scarcity theory contains a poverty cycle in which poverty itself causes poverty-reinforcing behaviors via specific psychological mechanisms (routes 1-2-7 and 5-6-7). Increased temporal discounting and overborrowing may ultimately reduce the overall payoff of the poor. Similarly, increased risk aversion can discourage long-term investments (e.g., in education or health) that would result in larger future payoffs. Subsequently, these behaviors reinforce the condition of poverty. As a consequence, it becomes more difficult to escape the situation of

\footnotetext{
${ }^{5}$ This definition highlights the subjective nature of scarcity. Others define (resource) scarcity as "the condition of having insufficient resources to cope with demands" (Zhao and Tomm 2018, p. 2) or "a discrepancy between one's current level of resources and a higher, more desirable reference point" (Cannon et al. 2019, p. 105).

${ }^{6}$ We derived this framework from Mullainathan and Shafir (2013) and the literature overview of Shah (2015).

${ }^{7}$ In our review, we focus on the routes proposed by Mullainathan and Shafir (2013).
} 


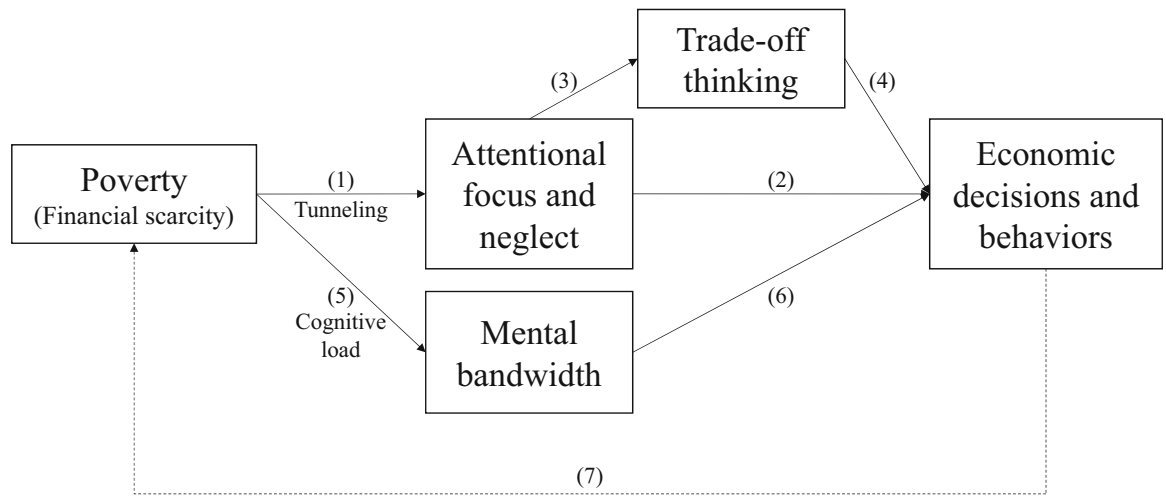

Fig. 1 Theoretical framework reflecting scarcity theory applied to poverty and economic decision making

poverty. Otherwise, the trade-off thinking route may positively affect the economic condition of the poor (route 1-3-4-7). We will discuss each of these three routes in more detail in Sects. 3-5.

Studies testing the hypotheses of scarcity theory reflect three types of study designs. First, laboratory experiments often exogenously induce scarcity by varying levels of resources (e.g., time, attempts, budgets) to be used in a task or game (see e.g., Shah et al. 2012, 2019; Spiller 2011; Zhao and Tomm 2017). Because the researcher has full control over the environment, this method helps to detect the causality of relationships and to gain insights into its underlying mechanisms. Second, cross-sectional and quasi-experimental studies investigate the consequences of poverty outside the lab. Cross-sectional difference studies typically investigate whether low- and high-income participants do react differently to a particular cue or a specific scenario (see e.g., Shah et al. 2015, 2018). Quasiexperimental studies typically investigate how variation in income interacts with other factors to reshape cognition and behaviors (see e.g., Mani et al. 2013a, b; Plantinga et al. 2018; Shah et al. 2015, 2018). Although these studies build on an ecologically valid approach, they face difficulties in establishing causality. Third, scientists use natural and field experiments to establish causality in a real-world environment. These studies typically test how fluctuations in income, wealth, or perceived financial situation affect outcomes (see e.g., Carvalho et al. 2016; Mani et al. 2013a, b; Ong et al. 2019). Each of these methods has its pros and cons, reason why it is important to provide a review of the integrative evidence of empirical studies.

We observe a mismatch between the poverty definition of scarcity theory and the instruments used in empirical studies to measure this concept. Building on the general scarcity definition ("having less than you feel you need"), scarcity theory defines poverty as "the gap between one's needs and the resources available to fulfill them" (Mani et al. 2013a, p. 976). Hagenaars and De Vos (1988) distinguish three types of poverty definitions. First, objective absolute poverty defines poverty as having less than a defined minimum income. Second, the objective relative poverty definition classifies people to be poor when having a relatively low income 
or when lacking certain commodities that are common in society. Third, subjective poverty refers to feelings or perceptions of having not enough to get along (see also Van Praag and Frijters 1999). Following this categorization of poverty definitions, scarcity theory builds on the subjective poverty definition, which concentrates on having not enough financial means to fulfill one's felt needs. Remarkably, almost all cross-sectional and quasi-experimental studies use income as a measurement instrument of poverty consistent with the objective relative poverty definition. ${ }^{8}$ This mismatch is remarkable because Mullainathan and Shafir (2013) already concluded that income is "at best a crude proxy for scarcity" (p. 72). Not all low-income individuals experience feelings of having less than they need. Furthermore, "some of those whom we classified as well off might well have been experiencing scarcity, for example, some were surely burdened by mortgage payments, credit card debt, college loans, or large families" (Mullainathan and Shafir 2013, p. 72). According to scarcity theory, the extent to which one feels that one has enough to fulfill one's needs defines subjective poverty, not the level of income. ${ }^{9}$

This mismatch between the poverty definition and chosen measurement instruments can be problematic. Using a measurement instrument that only roughly measures financial scarcity may prevent detecting the effects of financial scarcity on hypothesized outcomes. We recommend future empirical studies to use measurement instruments aligning the subjective poverty definition. To facilitate this alignment, an inventory of both existing measures and the development of new instruments is needed. ${ }^{10}$ The next three sections discuss the evidence for the propositions of our framework.

\section{Poverty, attention, and borrowing behavior}

Attention refers to "the flexible allocation of cognitive resources toward stimuli, internal representations, and outputs that are currently most important for the accomplishment of a behavioral goal" (Dosenbach and Petersen 2009, p. 655). Attention allocation is a central and unifying theme in behavioral economics (Gabaix 2019). Inattention may explain a broad range of behavioral phenomena ranging from inattention to prices to hyperbolic discounting. Mullainathan and Shafir (2013) hypothesize that feelings of scarcity influence the way attentional resources are allocated and subsequently affect economic decisions and behavior. This mechanism consists of two parts when applied to poverty: Poverty causes (1) an attentional focus on poverty-related issues that enhances resource efficiency and facilitates memory encouding, and (2) an attentional neglect that results in neglectful, forgetful, and overborrowing behaviors. The process of attentional focus and neglect is also referred to as tunneling (Mullainathan and Shafir 2013). Table 1

\footnotetext{
8 This claim is based on our literature review. As Tables 1, 2 and 3 shows, nearly all cross-sectional and quasi-experimental studies use income as measure of poverty. This claim does not carry over to other study designs (lab and natural experiments).

9 Of course, factors such as having a relatively low income compared to others or lacking commodities that are common in society will at least partly explain subjective poverty.

${ }^{10}$ See Hagenaars and De Vos (1988) for some existing subjective poverty measures that might be useful.
} 
(see Appendix) provides an overview of studies testing these propositions. We will discuss these findings in more detail below.

\subsection{Poverty leads to a greater focus}

Several studies have shown that feelings of scarcity induce a focus on scarcityrelated demands (see Zhao and Tomm 2018 for an overview). Two lab experiments showed this mechanism using manipulations of physiological scarcity. One experiment used manipulations of drink scarcity. Participants who were made feeling thirsty scored better on a recall task concerning drinking-related items compared to non-thirsty participants, while this was not the case for non-drinkingrelated items (Aarts et al. 2001). The same held in an experiment where participants were assigned to either longer or shorter periods of food deprivation. Fasting participants showed higher recall of food-related words, but not non-food-related words, compared to non-fasting participants (Radel and Clement-Guillotin 2012). Similarly, students with higher levels of financial anxiety paid relatively high attention to money-related cues (Shapiro and Burchell 2012). These results suggest that feelings of scarcity allocate attentional resources toward scarcity-related needs.

Shah et al. (2012) examined whether attention focusing also holds for povertyrelated scarcity. Their study consisted of several lab experiments where participants played budget-based games. To manipulate scarcity, participants were randomly allocated to small budgets (poor) or large budgets (rich). In one experiment, participants played the Angry Blueberries game. Participants had to fire blueberries with a slingshot to hit waffles. They earned points for each waffle that they hit. To manipulate levels of scarcity, participants were allocated to either small (3 per round) or large (15 per round) numbers of available shots. The poor (small number of shots) invested on average more time for aiming the first shot in each level of the game, suggesting that they focused and expended greater effort into the task at hand compared to more affluent participants (larger number of shots). ${ }^{11}$ Shah et al. (2019) replicated this finding using a larger sample underpinning the robustness of this result. A study by Zhao and Tomm (2017) provides additional evidence for the hypothesis by tracking visual attention. In one experiment, participants were randomly assigned to either a small $(\$ 20)$ or a larger $(\$ 100)$ price budget and were asked to place an order from a hypothetical restaurant menu. Using an eye-tracking technique to measure visual attention, they found that participants under scarcity spent significantly more time focusing on scarcity-related information (e.g., prices) than participants under abundance. Overall, these findings show that feelings of

\footnotetext{
11 Additionally, Shah et al. (2012) conducted a lab experiment where participants were allocated either small or large accounts of guesses in a word puzzle game. The authors proposed that small-budget participants would engage more deeply in the game which might cause cognitive exhaustion. Indeed, this initial study shows that poor participants performed worse compared to richer participants on a cognitive control task. However, this result was not replicated in studies containing much larger samples (Camerer et al. 2018; Shah et al. 2019).
} 
scarcity serve to allocate one's attention to scarcity-related issues, irrespective of the scarcity domain. ${ }^{12}$

This mechanism can be translated into the real-world environment of poverty (Shah 2015; Shah et al. 2012). When having access to enough financial resources, basic expenditures such as groceries, rent payments, and utility bills do not require much attention and effort to manage. However, under financial scarcity these expenses might become urgent, pressing, and difficult to handle because one's financial resources are not enough to fulfill all needs. As a consequence, these activities capture one's attention, resulting in a greater focus to solve these issues. A recent study suggests that the poor mentally associate everyday experiences and activities with money. Shah et al. (2018) showed that lower-income people are more likely to think about the costs of everyday activities than higher-income people. Furthermore, these thoughts arise spontaneously (e.g., when thinking about visiting a doctor) and are hard to suppress. Overall, these results suggest that the poor are more focused on the economic dimension of activities, thus providing a fuller picture of the subjective experience of being poor.

Scarcity-induced focus seems to come with some benefits. First, it might enhance resource or performance efficiency, also referred to as "focus dividend" (Mullainathan and Shafir 2013). In the Angry Blueberries study, participants with smaller budgets earned on average more points per shot and were thus more efficient than participants with larger budgets. Second, scarcity-induced focus might facilitate memory-encoding of task-relevant information. In the restaurant menu study, Zhao and Tomm (2017) found that participants with a smaller budget were significantly better at recalling scarcity-related information (e.g., prices) afterward than participants with larger budgets. ${ }^{13}$ This finding might explain why low-income people are more likely to know the starting price of a taxi than high-income individuals, despite the fact that they take taxis less frequently (Mullainathan and Shafir 2013).

Lichand and Mani (2020) investigated the effect of scarcity on attention allocation outside the lab. In a field study among Brazilian farmers who regularly face periods of droughts, the authors investigated the differential effects of income uncertainty and income level on tunneling. To examine the impact of income uncertainty, they exploited exogenous variation in daily rainfall. They found that participants exposed to less rainfall were more likely to tunnel (i.e., scarcity-related demands captured their attentional resources) than participants facing more rainfall. Additionally, they incorporated a lab-in-the-field experiment in which randomly half of the participants were induced with drought-related worries. Similar to the field study, they found that induced scarcity-related worries led to tunneling. Furthermore, in the same experimental setting, they investigated the impact of income level on tunneling using variation in a payday of a conditional cash transfer

\footnotetext{
12 A study of Sharma and Alter (2012) suggests that financial scarcity elicits a greater focus on scarce cues more generally. Participants were asked to recall a situation in which they were financially worse (better) off than their peers. Next, financially deprived participants were more likely to attend to and consume scarce rather than abundant stimuli and goods. These results suggest that financial scarcity leads to paying more attention to what is scarce in the environment.

13 This finding also generalized to another scarcity domain (calorie scarcity).
} 
program. ${ }^{14}$ They found that participants were more likely to tunnel in the period before payday than after payday. More specifically, the effect sizes were larger closer to payday. Overall, the authors conclude that both a low level of income and greater uncertainty in income induces tunneling.

We provide two methodological notes to these findings. First, variation in payday seems not to reflect variation in income levels (as proposed by the authors), because the amount of the cash transfer did not differ between experimental groups. We suggest that variation in payday rather reflects variation in liquidity constraints as households are more likely to face liquidity problems before than after payday. Second, the tunneling measure showed some inconsistencies. Tunneling was not directly observed, but derived from performance on a number of tasks. Although the overall effect of variation in rainfall on the tunneling index was significant, the effects on individual measures differed and for some measures even pointed in the opposite direction. This questions the validity of the tunneling measures. Furthermore, the effects of variation in rainfall on the individual tunneling measures were quite different from that of induced drought-related thoughts, suggesting that different mechanisms are at play.

\subsection{Poverty leads to neglect of other useful information}

Scarcity theory hypothesizes that a greater focus on pressing needs comes at a cost: Scarcity-induced focus leads to neglect of other useful information. Studies so far have not provided clear evidence for this proposition. Shah et al. (2012) examined this hypothesis using an experiment called "Family Feud." In this game, participants earned points for guessing popular answers to survey questions. Participants were allocated either small or large time budgets. Furthermore, some participants got a preview of questions of future rounds, others not. While the rich performed better with than without previews, no differences were found for poorer participants. This finding suggests that poorer participants did not pay enough attention to future issues, possibly because they focused more on the current question. However, in their high-powered replication study, Shah et al. (2019) found that richer participants performed only slightly better with than without previews. Furthermore, they did not find significant differences between poor and rich participants. Overall, these studies provide only very weak evidence for the hypothesis that scarcity-induced focus leads to attentional neglect of future events. We note that these studies have only tested this hypothesis indirectly because (visual) attention of the participants was not directly observed.

To solve this issue, Zhao and Tomm (2017) used eye-tracking to measure visual attention in their restaurant menu experiment, as discussed above. Participants under scarcity not only spent more time on scarcity-related information (e.g., prices) but also less time on other useful information (e.g., calorie information) than participants under abundance. Importantly, they were also more likely to neglect beneficial information (e.g., a discount placed at the bottom of the menu card) that would have alleviated the condition of scarcity. These findings suggest that scarcity

\footnotetext{
${ }^{14}$ More specifically, the authors exploited variation in the timing of monthly Bolsa Família payments.
} 
not only leads to a greater focus on scarcity-related information but also results in attentional neglect of other useful information. Additional experiments of Zhao and Tomm (2017) provide a richer picture of how scarcity induces neglect of useful information apart from the narrow focus on scarce resources. They showed that people under time scarcity were less likely to detect time-saving cues and more likely to forget previous instructions than people under abundance. These results suggest that scarcity impairs both information detection and prospective memory.

\subsection{Poverty leads to overborrowing}

Scarcity theory predicts that poverty leads to overborrowing via attentional focus and neglect. Shah et al. (2012) examined this hypothesis using two lab experiments. In the first experiment, participants played a follow-up of the Angry Blueberries game. Participants were not only randomly assigned to small or large budgets of shots but also to some borrowing options (no borrowing, borrowing shots with or without paying interest). Importantly, borrowing was a choice, so participants could neglect this opportunity. Results showed that the poor borrowed a higher proportion of their budget than the rich and gradually increased borrowing when their time budget shrunk. Furthermore, participants performed best when not having the opportunity to borrow, worse when they could borrow without interest, and worst when they could borrow against interest. Thus, borrowing under scarcity was counterproductive, especially when it was expensive. Meanwhile, the rich performed similarly under these conditions. In the second experiment, they examined the same mechanism using a follow-up of the Family Feud game. In this version, some of both the time-rich and time-poor participants could borrow time from future rounds while others could not. Again, they found that scarcity itself led people to overborrow and enter into cycles of debt, while this behavior did not happen under abundance. Importantly, these results were replicated in their highpowered study (Shah et al. 2019), although the effect sizes were smaller than in the initial study. Overall, these studies provide consistent evidence from the lab that scarcity leads to overborrowing.

These decision-making patterns seem to reflect the choices of people living in the context of financial scarcity. Attention is allocated to the most pressing financial problems and needs. Future needs loom far away. From this point of view, borrowing, even at high-interest rates, appears to be a proper solution to meet the pressing needs. However, the Angry Blueberries experiments show that borrowing might be counterproductive in the long run. It suggests that people may pay too little attention to the future implications of borrowing as a result of facing financial scarcity. This may explain why the poor rely on payday loans even when annualized costs of these loans exceed $7000 \%$ (Skiba and Tobacman 2008).

However, the mechanism underlying the effect of scarcity on borrowing behavior remains unclear. Scarcity theory proposes that this effect is the result of attentional focus and neglect. The initial Angry Blueberries study of Shah et al. (2012) provides some correlational evidence that attentional focus predicts borrowing behavior. They found that for budget-poor participants, spending more time on aiming a shot was associated with subsequently borrowing more shots. However, this result was 
not replicated in their larger-sample study (Shah et al. 2019). Although the Angry Blueberries studies showed that scarcity leads to a greater focus on scarcity-related issues, it remains unclear whether this mechanism also explains the borrowing behavior of the poor participants. Future lab studies should examine the exact mechanism underlying the effect of scarcity on overborrowing. Furthermore, the literature contains only lab studies providing evidence for the effect of scarcity on overborrowing. Field studies are needed that investigate the impact of scarcity on borrowing behavior in real-world settings.

In summary, lab studies provide consistent evidence that scarcity leads to a greater focus and causes overborrowing. Evidence that scarcity leads to attentional neglect is weaker. We recommend future lab studies to test this proposition further and to find out under what circumstances this proposition holds. Importantly, a large gap exists between scarcity inductions in lab experiments (e.g., manipulating budgets in the Angry Blueberries game) and facing financial scarcity in real life. The gap might limit the extrapolation of findings of lab experiments to real-world poverty. Specifically, these lab experiments differ from real life in duration (short vs. longer), frequency (once vs frequently), and severity (facing scarcity in a game vs. real life) of experiencing scarcity. To solve this problem, we recommend designing lab settings that better reflect facing scarcity in the daily lives of the poor. Furthermore, lab studies are needed to identify the exact mechanism underlying the effect of scarcity on overborrowing. So far, studies investigating the attentional mechanism outside the lab are scarce. Studies in real-world contexts are needed to examine the ecological validity of this mechanism. As discussed above, the field study of Lichand and Mani (2020) provides some evidence for differential effects of income level and income uncertainty on attention allocation, although the study comes with some methodological issues. More studies are needed to clarify whether the attentional mechanism holds in the real world and underlies the impact of poverty on borrowing decisions.

\section{Poverty, trade-off thinking, and consumption decisions}

Standard microeconomic theories build on the rationale that all people face scarcity and consequently have to make trade-offs between consumption options as no individual has access to unlimited financial resources. Thus, buying a particular product comes with opportunity costs, meaning that, by spending on one good, one forgoes another consumption good. However, behavioral research has shown that people often neglect these opportunity costs when making consumption decisions in real life (Frederick et al. 2009). Scarcity theory hypothesizes that poverty induces trade-off thinking, which creates a more stable frame of value and makes the poor less prone to some inconsistencies in making consumption decisions. As a consequence, the poor's decision-making processes align better with microeconomic assumptions resulting in more consistent choices and higher utility within a given budget. Next, we discuss the evidence for each of these predictions (see Table 2 for an overview). 
Some empirical investigations support the hypothesis that poverty induces tradeoff thinking. Compared to higher-income people, lower-income individuals report more trade-off thinking in case of hypothetical purchases (Mullainathan and Shafir 2013) and deciding about their willingness to pay for a product (Shah et al. 2015). The proposed underlying mechanism is that the poor naturally think about trade-offs because they face tight budgets (Mullainathan and Shafir 2013; Shah et al. 2015). In deciding about buying a product, alternative consumption options come quickly to the top of their mind. Individuals who experience abundance tend to pay less attention to opportunity costs because their budgets do not feel as limited. Findings of Spiller (2011) suggest that this is not the result of pre-existing differences between the rich and the poor. In a lab experiment, participants were more likely to pay attention to opportunity costs in performing a shopping task when randomly assigned to weekly (tighter) compared to monthly (more extensive) budget frames. Similarly, participants with a smaller budget (\$10) were more likely to consider opportunity costs when deciding about ordering items from a hypothetical breakfast menu than participants with a larger budget (\$40). These results suggest that scarcity alters people's valuation by directing attention to opportunity costs, implying that it is indeed scarcity that drives trade-off thinking and not pre-existing (wealth) differences between people.

Scarcity theory hypothesizes that if the poor are more likely to use trade-offs, it will make them less susceptible to irrelevant context features in consumption decisions. Two studies support this idea. In a series of experiments, Shah et al. (2015) showed that low-income people were less susceptible to irrelevant features in valuing offers, items, and situations. ${ }^{15}$ Some of these experiments revealed that the poor are less susceptible to relativity bias. Participants were asked about their willingness to travel a certain amount of time to another shop for a fixed amount of discount $(\$ 50)$ on a particular purchase price $(\$ 300, \$ 500$, or $\$ 1,000)$. Participants were randomly assigned to one of these price conditions. According to standard economic theory, the hypothetical question implies a trade-off between the costs (travel a certain amount of time) versus the benefits (for a certain amount of discount). The original purchase price should be seen as a "supposedly irrelevant factor" (Thaler 2015). In line with previous findings of Tversky and Kahneman (1981), higher-income participants were more likely to travel to obtain the discount on lower purchase prices, suggesting that they valued the offer in relative terms. However, lower-income participants were less sensitive to the proportional size of the discount. The poor seem to value the real trade-off of this question better, making them less susceptible to the relativity bias. Another study found similar response patterns for citizens of low- and middle-income countries as for lowincome U.S. residents, although differences in wealth within countries seem not to play a role (World Bank 2015). Similarly, Lichand and Mani (2020) found that Brazilian farmers were less susceptible to the relativity bias before than after

\footnotetext{
15 This finding not only held under financial scarcity but also under scarcity of time and food. People facing scarcity (limited time or a diet) showed fewer inconsistencies in valuing loss of time or fattening in fast-food-frames.
} 
payday. ${ }^{16}$ Overall, trade-off thinking seems to create a more consistent internal valuation standard while neglecting irrelevant external effects.

To what extent are these patterns incentive-compatible and confirmed in the field? To our best knowledge, only one field study examined whether people under scarcity are less susceptible to inconsistencies in consumption decisions. Fehr et al. (2019) found that facing financial scarcity reduces exchange asymmetries (also known as the endowment effect). In a large-scale study among Zambian farmers, interviewers gave participants halfway through the survey randomly one of two similarly-valued items as compensation for their participation. At the end of the survey, the interviewers offered them the opportunity to exchange the given item for an alternative good. Standard microeconomic theory predicts that half of the people will trade the endowed for the offered product because they received the less preferred item (Kahneman et al. 1991). ${ }^{17}$ However, the authors found strong evidence for the existence of exchange asymmetries: A significantly larger share of participants than predicted did not exchange their product. Importantly, exploiting ecological variation in financial scarcity around harvest, they found that participants were less susceptible to the endowment effect pre-harvest (when farmers face relative financial scarcity) than post-harvest (when farmers face relative abundance). This finding was robust under other sources of variation in financial scarcity (cross-sectional differences in wealth and experimental variation in liquidity constraints). These findings suggest that under financial scarcity people tend to pay more attention to the trade-off between the endowed and offered good, which subsequently reduces the endowment effect. As a consequence, the quality of decision making improves under scarcity.

However, not all studies support the hypothesis that the poor are less sensitive to inconsistencies in decision making. Some experiments conducted by Shah et al. (2015) did not reveal differences between higher- and lower-income participants. In one of these experiments, they tested whether lower-income individuals are less susceptible to the anchoring effect than higher-income individuals. Treatment group participants valued items after being exposed to an arbitrary anchor (a random number), while the control group did the same without this anchor. Contrary to their expectations, they did not find that lower-income participants were less sensitive to the anchoring effect. ${ }^{18}$ Similarly, they did not find significant differences between both income groups for the mental budgeting effect in the lost ticket scenario (Tversky and Kahneman 1981).

Furthermore, the results of Plantinga et al. (2018) do not support the proposition of scarcity theory that poverty induces trade-off thinking. They found equal rates of opportunity cost neglect among low-income and high-income people. In a series of high-powered experiments, they asked participants whether they would buy a

\footnotetext{
16 Similarly, farmers were more likely to use proportional thinking after being exposed to little rainfall compared to more rainfall. We note that the authors used the relativity bias task as part of a tunneling measure (see Sect. 3).

17 This prediction assumes that half of those who are indifferent between both goods will also exchange.

18 In line with this finding, Lichand and Mani (2020) did not find differences in sensitivity to the anchoring effect before versus after payday. We note that they incorporated the anchoring measure into a cognitive load index measure (see Sect. 5.2).
} 
particular product (e.g., a DVD or tablet) at a particular price. As a manipulation, some participants were reminded of the opportunity costs of this hypothetical purchase while others were not. ${ }^{19}$ They hypothesized that this reminder would have a smaller effect on the willingness to buy the product for lower-income than for higher-income individuals. If the poor use trade-off thinking in their decisionmaking process about the offer, they would naturally think about the opportunity costs. However, they did not find evidence that the poor show less opportunity cost neglect than the rich. High-income and low-income participants showed an equally strong decrease in willingness to buy in response to the reminder. This result was robust under both objective and subjective poverty measures and to different types and prices of the offered products. Importantly, this result contradicts the finding of Spiller (2011) that people are more likely to consider opportunity costs when facing financial constraints.

We provide two methodological notes to the findings of Plantinga et al. (2018). First, the results might have suffered from hypothetical bias. People may apply different decision processes in hypothetical purchasing scenarios compared to realworld decision contexts. Specifically, we question whether the hypothetical decision context did activate the needs threat, which is pivotal in detecting the effects of financial scarcity on outcomes. Otherwise, Frederick et al. (2009) found that people behave similarly when purchasing decisions are incentivized compared to hypothetical choices. Second, the quasi-experimental design used income as the predicting variable, which serves only as a rough proxy of financial scarcity (as discussed in Sect. 2). Third, the quasi-experimental design of their study does not allow drawing final conclusions about causality as their scarcity measure was based on existing rather than manipulated income levels. Importantly, these methodological notes also apply to the studies of Shah et al. (2015) and Mullainathan and Shafir (2013), discussed before. Their study designs also involved hypothetical decision scenarios and they used existing income levels as scarcity measure.

Overall, the literature does not provide an unambiguous conclusion regarding the proposition of scarcity theory that poverty induces trade-off thinking. Results of most studies underpin this proposition showing that low-income people report more trade-off thinking (Mullainathan and Shafir 2013; Shah et al. 2015) and value offers and products more consistently (Shah et al. 2015) than higher-income individuals. Similarly, Fehr et al. (2019) showed that people facing financial scarcity are less susceptible to the endowment effect than when they face financial abundance. However, other studies found that high- and low-income groups are equally sensitive to opportunity cost neglect (Plantinga et al. 2018) and the anchoring and mental budgeting effect (Shah et al. 2015). Methodological issues prevent drawing a firm conclusion. We recommend future studies to use measures aligning the poverty definition of scarcity theory and to design experiments incorporating incentivized consumption choices close to real-world contexts. ${ }^{20}$ Finally, future research should clarify when and to what extent trade-off thinking guides the decisions of the poor.

\footnotetext{
19 This scenario was previously used by Frederick et al. (2009).

20 The study of Fehr et al. (2019) can serve as a good example of such a field study.
} 


\section{Poverty, mental bandwidth, and economic decision making}

Mental bandwidth is an umbrella term and could be described as the cognitive ability to perform higher-level decisions and behaviors (Schilbach et al. 2016). Mental bandwidth also referred to as cognitive function, includes two components: cognitive capacity and executive control. Cognitive capacity, closely related to fluid intelligence, embraces the ability to solve problems and to reason logically. Executive control (also called cognitive control or executive function) refers to a set of mental processes that enable people to manage their cognitive activities (Carter et al. 1997; Schilbach et al. 2016). Executive control comprises three basic functions: (1) working memory operations to keep information retrievable, (2) inhibitory control to override impulses and automatic responses, and (3) cognitive flexibility to switch between tasks and perspectives (Diamond 2013). Executive control enables people to control their impulses, to multitask, to self-monitor, and to focus. So both cognitive capacity and executive control are at the core of decision making (Benjamin et al. 2013; Dohmen et al. 2010, 2018). Scarcity theory applied to poverty hypothesizes that poverty reduces mental bandwidth (i.e., cognitive capacity and executive control), which subsequently increases time discouting and risk aversion. Below we will discuss the evidence for these hypotheses (see Table 3 for a literature overview).

\subsection{Poverty reduces mental bandwidth: initial findings}

Scarcity theory hypothesizes that poverty causally impairs cognitive capacity and executive function. Initial findings of Mani et al. (2013a) confirm this hypothesis. Their research consists of two complementary studies: A lab study among shoppers of a mall in New Jersey (USA) and a field study involving Indian farmers. Their lab experiment aimed at examining the impact of facing financial challenges. Participants were allocated either large (e.g., an immediate $\$ 1500$ car repair) or small financial challenges (same but \$150) and were asked to think about solutions to finance it. While thinking about these scenarios, participants had to perform two psychological tests measuring fluid intelligence (IQ) and inhibitory control. ${ }^{21}$ While facing the hard financial challenge, low-income participants scored significantly worse on both tasks compared to higher-income people, while no differences were found while facing the small financial challenge. The magnitude of the effect on fluid intelligence (cognitive capacity) was remarkably high, comparable to a difference of 13-14 IQ points. The decrease in correct presses in the inhibitory control task was $20 \%$ points on average in the case of the "hard" financial challenge as compared with the easy financial challenge.

The proposed mechanism is that the hard financial challenge triggers thoughts of scarcity by low-income participants, bringing monetary issues to the top of mind,

\footnotetext{
${ }^{21}$ Fluid intelligence was measured using Raven's Matrices test, in which participants had to choose which shape was missing from a sequence of shapes. Inhibitory control was measured using a spatial incompatibility task. Participants had to alternate between congruent and incongruent actions. For some stimuli, they had to press a button on the same side of the screen. For other stimuli, they had to press a button on the opposite side.
} 
and temporarily leaving less mental bandwidth for other tasks. Richer people, who have more space in their budgets to solve the immediate car bill problem directly, are not required to put much cognitive effort to the challenge. Some additional experiments ruled out the possibility of anxiety for large numbers, (no) payment for correct test responses, and the impact of the cognitive tests themselves as alternative explanations. The effects were equally large in the replication studies. Overall, these results suggest that poverty-related monetary concerns directly and temporarily impair cognitive function.

The field study tried to deal with external validity by examining the relationship between poverty and cognitive function in a natural setting. The income of Indian sugarcane farmers largely depends on the revenues of the harvest. Consequently, they face more monetary concerns before than after harvest, as evidenced by substantially higher loan rates and higher rates of reported trouble with paying ordinary bills. The farmers were interviewed twice: before and after harvest. Both interviews incorporated a fluid intelligence test and an inhibitory control task. ${ }^{22}$ Before harvest, the same farmers performed significantly worse on the cognitive control task than after harvest. More specifically, they made 15\% more errors and were $11 \%$ slower in responding. Furthermore, participants scored significantly lower on the fluid intelligence test, corresponding with a decline of 9-10 IQ points. Although their research design could not inherently rule out potential confounds, the authors argue that the results cannot be fully explained by factors like learning effects, stress, or physical exertion. They conclude that poverty itself impedes cognitive function. So scarcity of financial resources results in monetary challenges that require mental bandwidth to address, leaving less available bandwidth for other activities.

How does financial scarcity impair cognitive function? Scarcity theory proposes that cognitive load underlies the impact of poverty on cognitive capacity and executive control (Gennetian and Shafir 2015; Mani et al. 2013a; Mullainathan and Shafir 2013; Schilbach et al. 2016). Mental bandwidth can be taxed when the mind of people has to deal with too many demands and disruptions. Cognitive load tends to affect both aspects of mental bandwidth in a negative way [see Gennetian and Shafir (2015) for an overview in light of scarcity theory]. Poverty can produce cognitive load via both internal and external sources. Scarcity theory follows the internal cognitive load mechanism. ${ }^{23}$ Living in poverty means that one has to deal

\footnotetext{
22 Cognitive capacity was measured using Raven's Matrices test (same as in the shopping mall study). Inhibitory control was measured using a numerical Stroop task which is appropriate to test low-literacy participants. To perform well on the test, participants had to neglect their automatic response. When they see 444 on the screen, they had to respond with the number of digits (3) instead of the digit 4 (the intuitive response).

23 Scarcity theory focuses on the financial and material dimensions of poverty, more specifically on the effects of feelings of having less than one needs. This neglects the social context (social class, stigmatization), physiological issues (lack of nutrition) and physical obstacles (lack of sleep) that surround individuals living in poverty. These may create additional taxes on people's mental bandwidth. Beyond the scope of scarcity theory, poverty may also induce cognitive load via these external stimuli. Recent studies have begun to unravel how poverty impairs cognitive function and economic performance via a lack of sleep (Bessone et al. 2020) and background noise (Dean 2020). See Dean et al. (2019) for a literature overview and a discussion of other mechanisms.
} 
with many monetary and non-monetary concerns attracting attention, like managing income volatility and payment deadlines, juggling expenses, and making difficult trade-offs in consumption. Additionally, low-income individuals dwell more upon their financial problems (Johar et al. 2015) and worry more about their financial future (de Bruijn and Antonides 2020). These preoccupations consume cognitive resources leaving less bandwidth for other activities.

While the results were striking, the studies of Mani et al. (2013a) have some important methodological limitations. First, the harvest study uses a simple pre-post research design as an identification strategy, thus lacking a control group. As a consequence, this study cannot fully rule out time trends or potential learning effects (Kremer et al. 2019; Wicherts and Zand Scholten 2013). Additionally, the used cognitive control task in the shopping mall study seems to be inappropriate due to ceiling effects caused by the simplicity of the task (Wicherts and Zand Scholten 2013). The used task did not discriminate well among individuals with higher cognitive control levels, specifically among higher-income individuals. As a consequence, Wicherts and Zand Scholten (2013) suggest that financial worries might also impair the cognitive control of higher-income individuals. ${ }^{24}$

\subsection{Poverty reduces mental bandwidth: findings from replication studies}

Since the initial findings of Mani et al. (2013a) were published, several studies have tried to replicate these results. These replication studies examining the impact of poverty on mental bandwidth show mixed results. Two studies examined the effect of poverty on cognitive capacity (fluid intelligence). First, as part of a study examining the impact of financial worries on risk-aversion, Dalton et al. (2019) also investigated the effect on fluid intelligence. To this end, they conducted a lab-in-thefield experiment among low-income small retailers in Vietnam. To induce financial worries, they used a similar method as Mani et al. (2013a) in which participants were randomly assigned to scenarios either involving large ("hard") or small ("easy") negative financial shocks. Contrary to the findings of Mani et al. (2013a), they did not find an effect of financial worries on fluid intelligence. Second, in their study among Zambian farmers, Fehr et al. (2019) also investigated the effects of financial scarcity on fluid intelligence. They found an inconsistent relationship between scarcity and fluid intelligence. Using cross-sectional differences in wealth, they found that lower wealth was associated with lower fluid intelligence. However, this finding did not replicate under seasonal (pre- vs. post-harvest) and experimental (disbursement of a consumption loan) variation in financial scarcity. ${ }^{25}$ Fluid

\footnotetext{
${ }^{24}$ Furthermore, Wicherts and Zand Scholten (2013) argued that the median split income procedure, applied by Mani et al. (2013a) to analyze the shopping mall experiment, was unnecessary and inappropriate. They reanalyzed the data without dichotomization of income for each of the three core experiments and found insignificant interaction effects (financial scenarios vs. income) on fluid intelligence. However, Mani et al. (2013b) responded that using binary income variables is standard when income data is noisy. Furthermore, they found a significant interaction effect on fluid intelligence when analyzing the data of the three core experiments together. Overall, we consider the effect on fluid intelligence as robust.

25 Overall, results of this study did confirm the trade-off thinking but not the mental bandwidth tax hypothesis of scarcity theory.
} 
intelligence scores did not significantly differ between pre-harvest compared to post-harvest conditions and before vs. after paying back a consumption loan. As a methodological limitation, we note that both the cross-sectional and pre-post (harvest) elements of the study might have failed to control for all potential confounders, while the experimental manipulation might not have been strong enough to evoke different levels in feelings of financial scarcity.

Four studies have investigated the effect of poverty on cognitive control, showing mixed results. Two of these studies did not reveal this effect. In their study among Zambian farmers, Fehr et al. (2019) found a similar inconsistent effect on cognitive control as for fluid intelligence. Although lower wealth was associated with lower levels of cognitive control, this result did not carry over to seasonal and experimental variation in financial scarcity. In another study, Carvalho et al. (2016) exploited natural variations in financial resources of U.S. low-income households around payday to examine the causal effect of financial circumstances on cognitive function. Households were randomly assigned to a before-payday or an after-payday survey. Baseline data of both studies show that households face tougher financial circumstances before payday compared to after payday (e.g., lower expenditures, cash holdings, and checking and savings account balances). However, results did not support the hypothesis of greater scarcity before payday impeding executive function. ${ }^{26}$ This holds both for the full sample as for more financially constrained subgroups. They conclude that short-term variations in financial circumstances did not diminish cognitive function.

However, the results of the latter study are subject to debate due to some methodological issues. First, variation in financial scarcity around payday might not be extreme enough for identifying the effects on cognitive function. As noted by Mani et al. (2013a), participants received up to four payments within a study month, of which one payment was chosen as the payday shock. Thus, around payday, participants faced only a small temporary shock in financial resources, especially when compared with participants in the harvest study of Mani et al. (2013a). Second, the payday research design might not have captured well the financial shocks around payday. Reanalyzing the data, Mani et al. (2020) show that insufficient control of the time of survey completion (before vs. after payday) seems to explain the non-results. Additionally, they found that executive control declined consistently as participants approached payday suggesting that facing financial scarcity causes cycles in executive control. We note that causal evidence is needed to fully rule out selection effects for this finding.

The results of two other studies confirmed the hypothesis that poverty impairs cognitive control. Ong et al. (2019) investigated the impact of a debt relief program (worth about three months of income) on cognitive functioning. They found that low-income Singaporean participants performed significantly better on a cognitive control task (Flanker task) after debt relief than before. Because this study used a pre-post design to identify treatment effects, similar to the harvest study of Mani

\footnotetext{
26 The cognitive function tests included the Cognitive reflection test (System 1 vs. System 2 thinking), the Flanker task (inhibitory control task), the working memory task, and the Numerical Stroop Task (cognitive control).
} 
et al. (2013a), learning effects and potential confounders might have affected the results. In their field study among Brazilian farmers, Lichand and Mani (2020) also investigated the impact of variations in rainfall (uncertainty) and payday (liquidity) on executive function. Farmers exposed to less rainfall worried more about rainfall and performed worse on cognitive control than farmers exposed to more rainfall. ${ }^{27}$ This drop in cognitive performance was equivalent to the gap between higher and lower educated farmers and was largest for low-income farmers. Furthermore, experimental induction of drought-related worries provided similar results. However, variation in payday did not affect executive function, except for farmers in the poorest regions. These results suggest that the minds of farmers facing less rainfall were loaded with thoughts about droughts and related financial uncertainty leaving less bandwidth for other activities. Additionally, the results suggest that income uncertainty (facing a lack of rainfall) dominates temporary liquidity constraints (around payday) as the main driver of the mental bandwidth tax caused by poverty.

Overall, the literature does not provide unambiguous evidence for the hypothesis that poverty reduces mental bandwidth. ${ }^{28}$ The above studies show some general results. First, the effect of poverty on fluid intelligence (cognitive capacity), initially found by Mani et al. (2013a), did not hold in replication studies (Dalton et al. 2019; Fehr et al. 2019). Second, studies that have investigated the impact of poverty on cognitive control show mixed results. Specifically, the effect was not found in studies exploiting (monthly) payday (Carvalho et al. 2016; Lichand and Mani 2020) or loan disbursement (Fehr et al. 2019), possibly because these financial shocks are too small to affect cognitive control meaningfully. Furthermore, these payday research designs did not capture financial uncertainty, which might primarily drive the adverse effect of poverty on cognitive control (Lichand and Mani 2020). As far as we know, no study attempted to fully replicate the findings of the shopping mall study of Mani et al. (2013a). ${ }^{29}$ We highly recommend a direct replication of this labin-the-field experiment in different economic environments (low-, middle-, and

\footnotetext{
27 More specifically, this study measured the effects on cognitive load using an index including scores on executive function (measured using an attention and inhibitory control task, and a working memory task) and an anchoring scenario. This latter measure deviates from others because it incorporates decisions that might be affected by cognitive load.

28 Some studies have found that particular cognitive functions even improve under scarcity. Dang et al. (2016) found that lower-income participants performed better than their more affluent counterparts on an information-integration categorization task after being induced with financial concerns. These findings suggest that poverty-induced thoughts improve procedural-based cognitive functions. Additionally, Zhao and Tomm (2017) showed that scarcity-induced focus facilitates memory-encoding of task-relevant information (see Sect. 3.1).

29 As far as we know, no study attempted to fully replicate the effects on both fluid intelligence and cognitive control in a similar experimental setting. As discussed, Dean et al. (2019) tried to replicate the effect of poverty on fluid intelligence using similar scenarios as Mani et al. (2013a). Because the literature might suffer from a publication bias, we searched for unpublished direct replications among Google references to the original paper of Mani et al. (2013a), last in December, 2020. Using the search term "replicate," we found 279 hits. Among these hits, we found three Master theses that attempted to directly replicate the effect of poverty on fluid intelligence. First, Graves (2015) did not find a significant effect of poverty on fluid intelligence. However, this replication was underpowered as noticed by the author. Second, Joy (2017) found a significant effect on fluid intelligence similarly to that of Mani et al. (2013a). Third, Plantinga (2014) did not find a significant effect of scarcity on both cognitive control and fluid intelligence in an online experiment.
} 
high-income countries) to gain insight into the robustness and external validity of these core findings.

Investigating the impact of poverty on mental bandwidth comes with methodological challenges, as we illustrated for each discussed study. We will shortly discuss these challenges and provide some directions to improve study designs. First, identification of treatment effects in real-world settings is challenging. Specifically, it is hard to isolate the effect of financial scarcity from that of other environmental and poverty-related causes. In designing field studies, researchers should consider the size and timing of the financial shock (Mani et al. 2020). The before-after differences in income or wealth due to the financial shock must be large enough and should be distinguishable from other shocks in income or expenditure. Additionally, researchers should consider whether the financial shock incorporates only shocks in levels of income, wealth, or liquidity, or also variation in financial uncertainty. Furthermore, alternative mechanisms (e.g., stress or motivational factors) might drive the (non)results and must thus be accounted for. Finally, researchers should a-priori seek ways to control for confounding variables. As is the case for all natural and field experimental studies, the quality of the control group strongly determines the quality of the results. Cash-transfer and basic income experiments might provide good opportunities to further examine the effect of poverty on mental bandwidth.

Second, measuring (effects on) cognitive function in field settings using psychological tasks is challenging. Performance on these tasks can be affected by pre-existing differences between experimental groups, learning effects, interviewrelated load, and floor and ceiling effects. In field settings, it is hard to fully control for these potential artifacts possibly leading to spurious effects. To solve this issue, we recommend to specify the cognitive mechanism under investigation a-priori and design the experimental study accordingly. Just adding a particular task or test (somewhere in the experimental procedure) to control for cognitive function as a potential explanation is not enough. Both lab and field studies should clarify that their study design captures the temporary effect of facing financial scarcity on mental bandwidth. Additionally, besides selecting a suitable control group, careful task selection and extensive piloting of the full test and interview procedure in the target population will help to minimize measurement problems (see Schilbach et al. 2016, and Dean et al. 2019, for overviews of suitable measures in field settings). Specifically, more attention is required for using the Raven test as a measurement instrument for fluid intelligence. All studies that measured the effect of poverty on fluid intelligence used a small subset of Raven matrices. However, it is unknown whether this abbreviated version did affect its reliability and validity. ${ }^{30}$ As the use of abbreviated Raven tests becomes increasingly popular in economic studies, we recommend the development of a standardized protocol. This protocol should shed light on selecting an appropriate number of matrices, whether or not including the progressive component of the original Raven test, and how the number of matrices affects the reliability and validity of the measure.

\footnotetext{
30 An abbreviated Raven test might perform almost equally well as the full version [see e.g., Bilker et al. (2012)]. However, it is unknown whether this is also the case for the versions used by Mani et al. (2013a), Dean et al. (2019), and Fehr et al. (2019).
} 


\subsection{Effects on economic decision making}

Time discounting and risk aversion are central elements of a broad range of economic decisions and behaviors. Several studies have shown that poverty increases both time discounting and risk aversion (see for an overview: Haushofer and Fehr 2014), while stress and negative affect (Haushofer and Fehr 2014) and rational responses to liquidity constraints (Carvalho et al. 2016) act as main underlying mechanisms. Scarcity theory hypothesizes that financial scarcity increases temporal discounting and risk aversion via cognitive load (Schilbach et al. 2016). ${ }^{31}$ We review the evidence for this hypothesis in two parts. First, we discuss evidence for the effect of cognitive load on both temporal discounting and risk aversion. We then review studies that have investigated the impact of financial scarcity on both outcomes and discuss whether cognitive load acts as an underlying mechanism.

Several studies have examined the impact of cognitive load on economic decision making. Some of these studies show how the decision-making process alters due to cognitive load. Cognitive load increases the reliance on shortcuts and heuristics in making choices (Kahneman 2011; Kahneman and Frederick 2002). According to the dual-processing model, cognitive load affects the controlling operations of the deliberative, reflective thinking system (System 2) resulting in increased reliance on the intuitive cognitive system (System 1). As a consequence, cognitive load potentially contributes to more errors in making decisions. Other studies address the question of how decisions change as a result of cognitive load. In their overview of empirical research, Deck and Jahedi (2015) show consistent evidence that cognitive load increases risk aversion. Evidence of a detrimental impact of cognitive load on temporal choices is mixed. While some studies suggest that cognitive load makes people more impatient, others do not support this hypothesis. Additional experiments conducted by Deck and Jahedi (2015) confirmed the above results and showed that cognitive load increased both risk aversion and money-related impatience.

Recently, researchers have begun to investigate the effect of poverty on economic decision making via the scarcity mechanism. Studies consistently show that facing financial scarcity increases temporal discounting (Bartos et al. 2018; Carvalho et al. 2016; Cassidy 2018; Ong et al. 2019). In a lab-in-the-field experiment among low-income Ugandan farmers, Bartos et al. (2018) investigated the effect of feelings of poverty on time discounting. Similar to the manipulation used by Mani et al. (2013a), these farmers were asked to think about the consequences of a scenario involving either a minor or a severe negative financial shock. Thereafter, they had to make a consequential decision about the timing of consuming entertainment early and delaying work effort. The results show that poverty-induced thoughts increased the farmers' preference for consuming entertainment earlier and delaying work effort, reflecting increased time discounting. The authors suggest that poverty-related thoughts directly reduce the ability to exercise

\footnotetext{
${ }^{31}$ This hypothesis was proposed by Schilbach et al. (2016) in their literature overview. We note that Mullainathan and Shafir (2013) did not provide specific predictions for these economic outcomes in their book.
} 
self-control, possibly via cognitive load. As the cognitive load was not directly measured, the exact mechanism still remains unclear. $^{32}$ In their study among Singaporean low-income households, Ong et al. (2019) showed that debt relief reduced present bias. However, they found only weak descriptive evidence of a mediating role of cognitive control underlying this effect. Other studies exploiting variation in payday (Carvalho et al. 2016) and windfalls (Cassidy 2018) found that poverty increased time discounting, but not due to cognitive load. Both studies propose that increased time discounting might reflect rational adaptations of the poor to changes in liquidity constraints rather than increased cognitive load.

The literature shows mixed evidence for the hypothesis that financial scarcity increases risk aversion, while evidence of cognitive load as an underlying mechanism is almost absent. In their study among Vietnamese retailers, Dalton et al. (2019) found that induced financial worries resulted in less risk-averse behavior. Furthermore, induced financial worries increased perceived stress, but not fluid intelligence (as discussed in Sect. 5.2). These results contradict both the hypothesis that financial scarcity increases risk aversion and findings that cognitive load increases risk aversion (Deck and Jahedi 2015). The authors propose that acute stress rather than cognitive load function as underlying mechanism. In their payday study, Carvalho et al. (2016) did not find an effect of financial scarcity on risk behavior. Only a study of Ong et al. (2019) found that debt relief reduced risk aversion. Similar to the effect on time discounting, suggestive evidence for a mediating role of cognitive control was weak.

Overall, the literature provides consistent evidence that financial scarcity increases temporal discounting, although evidence for cognitive load as underlying mechanism is weak. The literature does not provide consistent evidence that financial scarcity increases risk aversion, while evidence for the cognitive load as the underlying pattern is almost absent. These findings raise two issues. First, it is unclear how financial scarcity affects risk aversion as studies have shown positive (Ong et al. 2019), negative (Dalton et al. 2019), or no effects (Carvalho et al. 2016). A potential explanation is that risk behavior under financial scarcity might depend on whether the prospect involves a potential loss or gain (Adamkovič and Martončik 2017). Under poverty, people may have the tendency to take less risk for a potential financial gain (see e.g., Guiso and Paiella 2008) and to risk more to avoid a potential loss (Dalton et al. 2019). Thus, financial scarcity might strengthen loss aversion, which refers to people's tendency to prefer avoiding losses over acquiring equivalent gains (Kahneman and Tversky 1979). Indeed, lower income is associated with increased loss aversion (Vieider et al. 2019). Second, we question whether the effect of poverty on economic decision making operates via cognitive load. While our literature review shows consistent evidence that poverty increases time

\footnotetext{
32 The authors investigated whether attentional distraction underlies the effect on temporal discounting. However, they did not find differences between experimental conditions in decision-making time, distraction while making the decision, and patterns of information acquisition. In sum, these results do not support the view that poverty reduces attention. We note that this study does not provide a formal test of the attentional mechanism of scarcity theory as discussed in Sect. 3. The study tested whether povertyinduced thoughts reduced attention during the decision-making process, rather than changed attentional allocation.
} 
discounting, evidence for an effect of cognitive load on this outcome is mixed (Deck and Jahedi 2015). Similarly, the cognitive load literature confirms that cognitive load increases risk aversion (Deck and Jahedi 2015), but evidence for the hypothesis that financial scarcity increases risk aversion is mixed at best.

We note that financial scarcity can affect other economic outcomes via cognitive load. In a recent study among Indian workers, Kaur et al. (2019) randomized the timing of income payment while equalizing overall earnings. Workers receiving an earlier payment increased their productivity by $5.3 \%$ in comparison with workers who received their payments later. This increase in productivity almost doubled for poorer workers. Additionally, early payment reduced attentional errors suggesting that facing lower financial strain improves cognition and subsequently productivity. Future studies should examine what exactly happens when people face financial scarcity and how that affects cognition and subsequent economic decisions and behaviors.

\section{Discussion}

Our work aimed to review scarcity theory applied to the context of poverty. To this end, we reviewed the evidence for three fundamental hypotheses of this theory. Below, we will shortly summarize the status of the evidence for each hypothesis, discuss the overall status of scarcity theory applied to poverty, and provide some general directions for future research.

Scarcity theory applied to poverty hypothesizes that poverty affects economic decisions and behaviors via three mechanisms (see Fig. 1). We briefly state the status of the evidence for each relationship. As we showed in Sect. 3, lab studies provide consistent evidence that scarcity leads to a greater focus on scarcity-related demands, enhances resource efficiency, facilitates memory-encoding, and causes overborrowing. Evidence that scarcity leads to attentional neglect is weaker. It is still unclear whether overborrowing results from attentional focus and neglect. Additionally, evidence for the ecological validity of the attentional focus mechanism is weak as field studies examining this mechanism in real-world contexts are scarce. As discussed in Sect. 4, most studies confirmed that poverty induces trade-off thinking and subsequently results in more consistent consumption decisions. However, methodological issues and some inconsistent findings prevent a firm conclusion. As reported in Sect. 5, the literature provides mixed evidence for the hypothesis that poverty impairs cognitive capacity and executive control. Additionally, the literature consistently shows that financial scarcity increases time discounting, while evidence for a positive effect on risk aversion is mixed. However, the current literature does not support the view that cognitive load underlies the effect of financial scarcity on temporal discounting and risk aversion.

This overview brings us to a remaining question: How should we evaluate the overall status of scarcity theory? Following the definition of Kerlinger and Lee (2000), "a theory is a set of interrelated constructs, definitions, and propositions that present a systematic view of phenomena by specifying relations among variables, with the purpose of explaining and predicting the phenomena" (p. 11). We apply the properties of a useful theory proposed by Dennis and Kintsch (2007) to evaluate the 
status of scarcity theory applied to poverty. Building upon reasonable claims that cognitive resources are limited, scarcity theory applied to poverty provides an original, coherent, and parsimonious explanation that a single phenomenon (financial scarcity) explains a variety of behavioral phenomena (economic decisions and behaviors) operating via two core psychological mechanisms (tunneling and cognitive load). Furthermore, these mechanisms do not only operate under poverty but also under several other forms of scarcity (e.g., drink, food, and time scarcity). Importantly, the theory provides testable and falsifiable hypotheses. However, the theory lacks precision in defining key mechanisms (as researchers use different names, definitions, and operationalizations for the attentional and cognitive load mechanism) and predicting economic outcomes (which are rather empirically driven than theory-based). Furthermore, we showed that the theory does not fully accord with the available data. More specifically, while the literature provides (mainly) consistent evidence for the attentional focus and neglect mechanism and related borrowing and consumption behaviors, evidence for the cognitive load mechanism and associated behaviors is mixed at best. As the strength of a theory relies on the evidence, the current evidence limits the strength of scarcity theory.

We recommend two general lines for future research in additional to the specific recommendations in Sect. 2-5. First, more theoretical work is needed. Currently, scarcity theory is stated verbally. We recommend researchers to translate the theory into formal models (e.g., mathematical or computational models) to enforce precision in defining constructs and mechanisms and to predict economic outcomes. Second, future work should focus on improving our understanding of the mechanisms enforced by facing financial scarcity. Brain research might help to detect which brain activities underly the effect of facing scarcity on downstream behaviors. In an initial study, Huijsmans et al. (2019) found that a scarcity mindset is associated with increased activity in the orbitofrontal cortex (which encodes valuation processes) and decreased activity in the dorsolateral prefrontal cortex (which is known for its involvement in the executive functions). Additionally, we need to know whether other mechanisms are at play, besides tunneling and cognitive load, and how these mechanisms compete with each other. At least stress and negative affect seem to play a role (Haushofer and Fehr 2014) but it is unclear to what extent these mediators coincide with each other. Finally, future studies should deepen our understanding of when facing scarcity improves and when it impairs performance. Scarcity theory predicts that facing scarcity makes people both less (via trade-off thinking) and more (via attentional neglect and cognitive load) susceptible to biases in decision making. However, it is not fully clear how scarcity triggers either mechanism. For example, the shopping task (Spiller 2011) and the Angry Blueberries (Shah et al. 2012) experiment contained similar intertemporal choice contexts but predicted and found different results. We suggest that choice architecture might also play a role. Future studies should address this issue.

In conclusion, we have reviewed the evidence for the key propositions of scarcity theory applied to poverty and evaluated the overall status of this theory. Although scarcity theory coherently and parsimoniously explains how financial scarcity affects economic decisions and behaviors, the theory does not fully accord with the 
available data. In general, both building models and testing implications contribute to a virtuous cycle of theory development (Smaldino 2019). While building formal models will help to enforce precision, rigorous testing will help to unravel empirical patterns. We recommend increased efforts on both elements of the theory development cycle. Finally, these efforts will contribute to a stronger theory explaining how financial scarcity affects economic decision making.

\section{Appendix}

See Tables 1, 2 and 3.

Table 1 Literature overview of the impact of poverty on attention and economic behavior

\begin{tabular}{|c|c|c|c|}
\hline References & Type of study & $\begin{array}{l}\text { Scarcity induction method/ } \\
\text { identification strategy }\end{array}$ & Result \\
\hline $\begin{array}{l}\text { Shah et al. } \\
\text { (2012) }\end{array}$ & $\begin{array}{l}\text { Lab experiments } \\
N=56-143 \text { per study }\end{array}$ & $\begin{array}{l}\text { Games: Angry Blueberries } \\
\text { and Family Feud } \\
\text { Small and large budgets of } \\
\text { shots and time }\end{array}$ & $\begin{array}{l}\text { Scarcity leads to greater } \\
\text { focus, attentional neglect, } \\
\text { and overborrowing } \\
\text { "Confirmed" }\end{array}$ \\
\hline $\begin{array}{l}\text { Shah et al. } \\
\text { (2019) }\end{array}$ & $\begin{array}{l}\text { Lab experiments } \\
N= \pm 1,000 \text { per study } \\
\text { Self-replication of Shah } \\
\text { et al. (2012) }\end{array}$ & Idem & $\begin{array}{l}\text { Scarcity leads to greater focus } \\
\text { and overborrowing. Effects } \\
\text { on attentional neglect were } \\
\text { weaker/not robust } \\
\text { "Mainly confirmed"“" }\end{array}$ \\
\hline $\begin{array}{c}\text { Zhao and } \\
\text { Tomm } \\
(2017)\end{array}$ & Lab experiments & $\begin{array}{l}\text { Place a meal order from a } \\
\text { hypothetical menu: Large } \\
\text { and small price/calorie } \\
\text { budgets } \\
\text { Solve a series of digital } \\
\text { puzzles: Large and small- } \\
\text { time budgets }\end{array}$ & $\begin{array}{l}\text { Scarcity of money, calories, } \\
\text { and time caused a greater } \\
\text { focus on scarcity-related } \\
\text { information while inducing } \\
\text { neglect of other beneficial } \\
\text { information (e.g., scarcity- } \\
\text { reducing information) } \\
\text { "Confirmed" }\end{array}$ \\
\hline $\begin{array}{l}\text { Lichand } \\
\text { and } \\
\text { Mani } \\
(2020)\end{array}$ & $\begin{array}{l}\text { Natural experiment with } \\
\text { an integrated lab-in-the- } \\
\text { field experiment among } \\
\text { Brazilian farmers }\end{array}$ & $\begin{array}{l}\text { Identification strategies: } \\
\text { (1) income uncertainty: } \\
\text { (a) natural variation in } \\
\text { rainfall and } \\
\text { (b) experimental induction } \\
\text { of drought-related worries } \\
\text { (2) income level: variation in } \\
\text { payday } \\
\text { Outcome: tunneling }\end{array}$ & $\begin{array}{l}\text { Farmers facing lower rainfall } \\
\text { rates/induced with drought- } \\
\text { related worries were more } \\
\text { likely to tunnel than farmers } \\
\text { facing higher rainfall rates/ } \\
\text { in the control condition. } \\
\text { Furthermore, farmers } \\
\text { before payday were more } \\
\text { likely to tunnel than after } \\
\text { payday } \\
\text { "Confirmed" }\end{array}$ \\
\hline
\end{tabular}

We only incorporate studies with a clear link to poverty and economic decision making. See Cannon et al. (2019) for a complete literature overview of mechanisms and behaviors induced by resource scarcity. "(Not) confirmed" indicates whether the results of the study did (not) confirm the hypothesis that poverty/ scarcity leads to greater focus, attentional neglect, and overborrowing. 
Table 2 Literature overview of the impact of poverty on trade-off thinking and economic decision making

\begin{tabular}{|c|c|c|c|}
\hline Reference & Type of study & $\begin{array}{l}\text { Scarcity induction method/ } \\
\text { identification strategy }\end{array}$ & Result \\
\hline Spiller (2011) & $\begin{array}{l}\text { Lab } \\
\text { experiments }\end{array}$ & $\begin{array}{l}\text { Daily shopping task: Budget } \\
\text { frames (weekly vs. monthly) } \\
\text { Breakfast menu scenario: small } \\
\text { vs. larger budget in the wallet }\end{array}$ & $\begin{array}{l}\text { Participants under (perceived) } \\
\text { resource scarcity were more } \\
\text { likely to consider or report } \\
\text { opportunity costs than } \\
\text { participants under abundance } \\
\text { "Confirmed" }\end{array}$ \\
\hline $\begin{array}{l}\text { Mullainathan } \\
\text { and Shafir } \\
\text { (2013) }\end{array}$ & $\begin{array}{l}\text { Cross-sectional } \\
\text { differences }\end{array}$ & $\begin{array}{l}\text { Poverty measure: Income } \\
\text { Scenarios: } \\
\text { USA-study: Buying a TV } \\
\text { India-study: Buying a blender } \\
\text { and a TV }\end{array}$ & $\begin{array}{l}\text { Low-income participants were } \\
\text { more likely to report trade-off } \\
\text { thinking for buying a TV } \\
\text { (USA) and a blender (India) } \\
\text { than higher-income } \\
\text { participants. In India-study, no } \\
\text { differences found for buying a } \\
\text { relatively expensive product } \\
\text { (TV) } \\
\text { "Confirmed" }\end{array}$ \\
\hline $\begin{array}{l}\text { Shah et al. } \\
\text { (2015) } \\
\text { Study 1a }\end{array}$ & $\begin{array}{l}\text { Cross-sectional } \\
\text { differences }\end{array}$ & $\begin{array}{l}\text { Poverty measure: Income } \\
\text { Beer-on-the-beach scenario: } \\
\text { considerations for the purchase }\end{array}$ & $\begin{array}{l}\text { Lower-income participants were } \\
\text { more likely to name trade-offs } \\
\text { as main consideration } \\
\text { "Confirmed" }\end{array}$ \\
\hline $\begin{array}{l}\text { Shah et al. } \\
\qquad(2015) \\
\text { Studies 2-4 }\end{array}$ & $\begin{array}{l}\text { Quasi- } \\
\text { experimental } \\
\text { design }\end{array}$ & $\begin{array}{l}\text { Poverty measure: Income } \\
\text { Scenarios: Beer-on-the-beach, } \\
\text { proportional thinking, } \\
\text { dominance lottery, accessible } \\
\text { accounts }\end{array}$ & $\begin{array}{l}\text { Lower-income participants more } \\
\text { consistent in valuation of } \\
\text { products and less susceptible to } \\
\text { context effects } \\
\text { "Confirmed" }\end{array}$ \\
\hline $\begin{array}{l}\text { Shah et al. } \\
\text { (2015) } \\
\text { Studies S8 } \\
\text { and S9 }\end{array}$ & $\begin{array}{l}\text { Quasi- } \\
\text { experimental } \\
\text { design }\end{array}$ & $\begin{array}{l}\text { Poverty measure: Income } \\
\text { Scenarios: Mental budgeting, } \\
\text { anchoring }\end{array}$ & $\begin{array}{l}\text { No significant differences } \\
\text { between higher- and lower- } \\
\text { income participants found for } \\
\text { the anchoring and mental } \\
\text { budgeting effects } \\
\text { "Not Confirmed" }\end{array}$ \\
\hline $\begin{array}{l}\text { Plantinga } \\
\text { et al. (2018) }\end{array}$ & $\begin{array}{l}\text { Quasi- } \\
\text { experimental } \\
\text { design }\end{array}$ & $\begin{array}{l}\text { Poverty measures: Income, } \\
\text { subjective wealth, and } \\
\text { subjective social status } \\
\text { Scenario: willingness to pay for } \\
\text { attractive products } \\
\text { (manipulation: reminded of } \\
\text { opportunity costs) }\end{array}$ & $\begin{array}{l}\text { Rich and poor participants } \\
\text { showed an equally strong } \\
\text { decline in willingness to pay } \\
\text { when reminded of opportunity } \\
\text { costs. Finding robust for all } \\
\text { poverty measures } \\
\text { "Not Confirmed" }\end{array}$ \\
\hline
\end{tabular}


Table 2 continued

\begin{tabular}{|c|c|c|c|}
\hline Reference & Type of study & $\begin{array}{l}\text { Scarcity induction method/ } \\
\text { identification strategy }\end{array}$ & Result \\
\hline $\begin{array}{l}\text { Fehr et al. } \\
\text { (2019) }\end{array}$ & $\begin{array}{l}\text { Natural } \\
\text { experiment } \\
\text { (Zambian } \\
\text { farmers) }\end{array}$ & $\begin{array}{l}\text { Identification strategies: (1) } \\
\text { Cross-sectional variation in } \\
\text { wealth, (2) natural variation in } \\
\text { wealth due to harvest, and (3) } \\
\text { random variation in loan } \\
\text { disbursement }\end{array}$ & $\begin{array}{l}\text { Across all sources of variation, } \\
\text { greater financial scarcity was } \\
\text { associated with smaller } \\
\text { exchange asymmetries (i.e., } \\
\text { participants were more likely to } \\
\text { trade under scarcity) }\end{array}$ \\
\hline & & $\begin{array}{l}\text { Exchange asymmetry: Propensity } \\
\text { to trade a randomly endowed } \\
\text { item for an alternative at a later } \\
\text { moment }\end{array}$ & "Confirmed" \\
\hline
\end{tabular}

"(Not) confirmed" indicates whether the results of the study did (not) confirm the hypothesis that poverty/ scarcity increases trade-off thinking

Table 3 Literature overview of the impact of poverty on cognitive capacity and executive control

\begin{tabular}{|c|c|c|c|c|}
\hline Reference & Type of study & $\begin{array}{l}\text { Scarcity induction } \\
\text { method/identification } \\
\text { strategy }\end{array}$ & Outcome variable & Result \\
\hline \multirow[t]{2}{*}{$\begin{array}{l}\text { Mani } \\
\text { et al. } \\
(2013 a)\end{array}$} & $\begin{array}{l}\text { Study 1: Lab } \\
\text { experiment } \\
\text { (quasi- } \\
\text { experimental } \\
\text { design) }\end{array}$ & $\begin{array}{l}\text { Study 1: Income vs } \\
\text { scenario's: thinking } \\
\text { about hard vs. easy } \\
\text { financial challenge }\end{array}$ & $\begin{array}{l}\text { Study } 1 \text { and } 2 \text { : } \\
\text { Fluid } \\
\text { intelligence and } \\
\text { cognitive } \\
\text { control }\end{array}$ & $\begin{array}{l}\text { Study 1: poverty- } \\
\text { related thoughts } \\
\text { impair fluid } \\
\text { intelligence and } \\
\text { cognitive control of } \\
\text { lower-income, but } \\
\text { not of higher-income } \\
\text { participants }\end{array}$ \\
\hline & $\begin{array}{l}\text { Study 2: Natural } \\
\text { experiment (pre- } \\
\text { post design) }\end{array}$ & $\begin{array}{l}\text { Study 2: Shock in } \\
\text { income of Indian } \\
\text { sugarcane farmers } \\
\text { (pre- vs. post- } \\
\text { harvest) }\end{array}$ & & $\begin{array}{l}\text { Study 2: Participants } \\
\text { scored significantly } \\
\text { better on fluid } \\
\text { intelligence and } \\
\text { cognitive control } \\
\text { post-harvest than } \\
\text { pre-harvest } \\
\text { "Confirmed" }\end{array}$ \\
\hline $\begin{array}{l}\text { Carvalho } \\
\text { et al. } \\
\text { (2016) }\end{array}$ & $\begin{array}{l}\text { Natural experiment } \\
\text { (quasi- } \\
\text { experimental } \\
\text { design) }\end{array}$ & $\begin{array}{l}\text { Financial shock for } \\
\text { low-income US- } \\
\text { households: Before } \\
\text { vs. after payday }\end{array}$ & $\begin{array}{l}\text { Cognitive } \\
\text { function: } \\
\text { Working } \\
\text { memory, } \\
\text { inhibitory } \\
\text { control, and } \\
\text { cognitive } \\
\text { flexibility }\end{array}$ & $\begin{array}{l}\text { Participants surveyed } \\
\text { before and after } \\
\text { payday performed } \\
\text { similar on cognitive } \\
\text { function tasks } \\
\text { "Not Confirmed" }\end{array}$ \\
\hline
\end{tabular}


Table 3 continued

\begin{tabular}{llll}
\hline Reference & Type of study & $\begin{array}{l}\text { Scarcity induction } \\
\text { method/identification } \\
\text { strategy }\end{array}$ & \\
\hline
\end{tabular}

Ong et al. Natural experiment: Comparing low(2019) pre-post design income Singaporean participants before and after debt relief

Dalton Lab-in-the-field

et al. experiment

(2019) among lowincome retail entrepreneurs in Vietnam

Fehr et al. Cross-sectional (2019) differences, natural experiment, and field experiment
Induction of financial worries: hard vs. easy financial challenge scenario

\section{Identification}

strategies: (1) Crosssectional variation in wealth, (2) natural variation in wealth around harvest, and (3) random variation in disbursement of consumption loans
Cognitive control, Participants showed negative affect improved cognitive (anxiety), risk aversion, and present bias control and reduced negative affect, risk aversion, and present bias after debt relief

\section{"Confirmed"}

Fluid intelligence and risk aversion

Being exposed to financial worries did not affect fluid intelligence.

Entrepreneurs exposed to financial worries behaved less risk-averse than those in the control condition

\section{"Not Confirmed"}

Fluid intelligence

Inconsistent and cognitive control relationship between financial scarcity and cognitive function. Cross-sectional: Wealthier participants score better than poorer participants. No clear pattern for other sources of variation in financial scarcity

"Not Confirmed" 
Table 3 continued

\begin{tabular}{|c|c|c|c|c|}
\hline Reference & Type of study & $\begin{array}{l}\text { Scarcity induction } \\
\text { method/identification } \\
\text { strategy }\end{array}$ & Outcome variable & Result \\
\hline $\begin{array}{l}\text { Lichand } \\
\text { and } \\
\text { Mani } \\
(2020)\end{array}$ & $\begin{array}{l}\text { Natural experiment } \\
\text { with an integrated } \\
\text { lab-in-the-field } \\
\text { experiment } \\
\text { among Brazilian } \\
\text { farmers }\end{array}$ & $\begin{array}{l}\text { Identification } \\
\text { strategies: (1) } \\
\text { Income uncertainty: } \\
\text { (a) natural variation } \\
\text { in rainfall and } \\
\text { (b) experimental } \\
\text { induction of } \\
\text { drought-related } \\
\text { worries } \\
\text { (2) Income level: } \\
\text { variation in payday }\end{array}$ & $\begin{array}{l}\text { Executive } \\
\text { function } \\
\text { (Working } \\
\text { memory, } \\
\text { attention, and } \\
\text { inhibitory } \\
\text { control) }\end{array}$ & $\begin{array}{l}\text { Farmers exposed to } \\
\text { less rainfall/drought- } \\
\text { related worries } \\
\text { performed worse on } \\
\text { executive function } \\
\text { tasks than farmers } \\
\text { exposed to more } \\
\text { rainfall/control } \\
\text { condition. Variation } \\
\text { in payday (before vs. } \\
\text { after) did not affect } \\
\text { executive function } \\
\text { (except for the } \\
\text { poorest) } \\
\text { "Confirmed" }\end{array}$ \\
\hline
\end{tabular}

"(Not) confirmed" indicates whether the results of the study did (not) confirm the hypothesis that poverty/ scarcity impairs cognitive capacity/executive control

Funding This work was supported by the Dutch Research Council [023.005.060 to E.B.].

\section{Compliance with ethical standards}

Conflicts of interest The authors declares that they have no competing interest.

Open Access This article is licensed under a Creative Commons Attribution 4.0 International License, which permits use, sharing, adaptation, distribution and reproduction in any medium or format, as long as you give appropriate credit to the original author(s) and the source, provide a link to the Creative Commons licence, and indicate if changes were made. The images or other third party material in this article are included in the article's Creative Commons licence, unless indicated otherwise in a credit line to the material. If material is not included in the article's Creative Commons licence and your intended use is not permitted by statutory regulation or exceeds the permitted use, you will need to obtain permission directly from the copyright holder. To view a copy of this licence, visit http:// creativecommons.org/licenses/by/4.0/.

\section{References}

Aarts, H., Dijksterhuis, A., \& Vries, P. (2001). On the psychology of drinking: Being thirsty and perceptually ready. British Journal of Psychology, 92(4), 631-642. https://doi.org/10.1348/ 000712601162383.

Adamkovič, M., \& Martončik, M. (2017). A review of consequences of poverty on economic decisionmaking: A hypothesized model of a cognitive mechanism. Frontiers in Psychology, 8, 1-13. https:// doi.org/10.3389/fpsyg.2017.01784.

Banerjee, A. V., \& Duflo, E. (2007). The economic lives of the poor. Journal of Economic Perspectives, 21(1), 141-167. https://doi.org/10.1257/jep.21.1.141.

Bartos, V., Bauer, M., Chytilová, J., \& Levely, I. (2018). Effects of poverty on impatience: Preferences or inattention? CERGE-EI working paper 623. https://doi.org/10.2139/ssrn.3247690 
Benjamin, D. J., Brown, S. A., \& Shapiro, J. M. (2013). Who is "behavioral"? Cognitive ability and anomalous preferences. Journal of the European Economic Association, 11(6), 1231-1255. https:// doi.org/10.1111/jeea.12055.

Bertrand, M., Mullainathan, S., \& Shafir, E. (2006). Behavioral economics and marketing in aid of decision making among the poor. Journal of Public Policy \& Marketing, 25(1), 8-23. https://doi. org/10.1509/jppm.25.1.8.

Bessone, P., Rao, G., Schilbach, F., Schofield, H., \& Toma, M. (2020). The economic consequences of increasing sleep among the urban poor. National Bureau of Economic Research working paper 26746. https://doi.org/10.3386/w26746

Bilker, W. B., Hansen, J. A., Brensinger, C. M., Richard, J., Gur, R. E., \& Gur, R. C. (2012). Development of abbreviated nine-item forms of the Raven's standard progressive matrices test. Assessment, 19(3), 354-369. https://doi.org/10.1177/1073191112446655.

Blalock, G., Just, D. R., \& Simon, D. H. (2007). Hitting the jackpot or hitting the skids: Entertainment, poverty, and the demand for state lotteries. American Journal of Economics and Sociology, 66(3), $545-570$.

Camerer, C. F., Dreber, A., Holzmeister, F., Ho, T.-H., Huber, J., Johannesson, M., et al. (2018). Evaluating the replicability of social science experiments in Nature and Science between 2010 and 2015. Nature Human Behaviour. https://doi.org/10.1038/s41562-018-0399-z.

Cannon, C., Goldsmith, K., \& Roux, C. (2019). A self-regulatory model of resource scarcity. Journal of Consumer Psychology, 29(1), 104-127. https://doi.org/10.1002/jcpy.1035.

Carter, A., Frye, D., Reznick, J. S., \& Zelazo, P. D. (1997). Early development of executive function: A problem-solving framework. Review of General Psychology, 1(2), 198-226. https://doi.org/10.1037/ 1089-2680.1.2.198.

Carvalho, L. S., Wang, S. W., \& Meier, S. (2016). Poverty and economic decision-making: Evidence from changes in financial resources at payday. American Economic Review, 106(2), 260-284. https://doi.org/10.1257/aer.20140481.

Cassidy, R. (2018). Are the poor so present-biased? Institute for Fiscal Studies working paper 18/24. https://www.ifs.org.uk/uploads/publications/wps/WP201824.pdf.

Dalton, P. S., Nhung, N., \& Rüschenpöhler, J. (2019). Worries of the poor: The impact of financial burden on the risk attitudes of micro-entrepreneurs. Journal of Economic Psychology. https://doi.org/10. 1016/j.joep.2019.102198.

Dang, J., Xiao, S., Zhang, T., Liu, Y., Jiang, B., \& Mao, L. (2016). When the poor excel: Poverty facilitates procedural learning. Scandinavian Journal of Psychology, 57(4), 288-291. https://doi.org/ 10.1111/sjop. 12292 .

de Bruijn, E. J., \& Antonides, G. (2020). Determinants of financial worry and rumination. Journal of Economic Psychology, 76, 102233. https://doi.org/10.1016/j.joep.2019.102233.

Dean, E. B., Schilbach, F., \& Schofield, H. (2019). Poverty and cognitive function. In C. B. Barrett, M. R. Carter, \& J.-P. Chavas (Eds.), The economics of poverty traps (pp. 57-118). Chicago: University of Chicago Press.

Dean, J. T. (2020). Noise, cognitive function, and worker productivity. Working paper. https:// joshuatdean.com/wp-content/uploads/2020/02/NoiseCognitiveFunctionandWorkerProductivity.pdf.

Deck, C., \& Jahedi, S. (2015). The effect of cognitive load on economic decision making: A survey and new experiments. European Economic Review, 78, 97-119. https://doi.org/10.1016/j.euroecorev. 2015.05.004.

Dennis, S., \& Kintsch, W. (2007). Evaluating theories. In R. J. Sternberg, H. L. Roediger III., \& D. F. Halpern (Eds.), Critical thinking in psychology (pp. 143-159). Cambridge: Cambridge University Press. https://doi.org/10.1017/CBO9780511804632.010.

Diamond, A. (2013). Executive functions. Annual Review of Psychology, 64(1), 135-168. https://doi.org/ 10.1146/annurev-psych-113011-143750.

Dohmen, T., Falk, A., Huffman, D., \& Sunde, U. (2010). Are risk aversion and impatience related to cognitive ability? American Economic Review, 100(3), 1238-1260. https://doi.org/10.1257/aer.100. 3.1238 .

Dohmen, T., Falk, A., Huffman, D., \& Sunde, U. (2018). On the relationship between cognitive ability and risk preference. Journal of Economic Perspectives, 32(2), 115-134. https://doi.org/10.1257/jep. 32.2.115.

Dosenbach, N. U. F., \& Petersen, S. E. (2009). Attentional networks. In Encyclopedia of neuroscience (pp. 655-660). Elsevier. https://doi.org/10.1016/B978-008045046-9.00204-7 
Fehr, D., Fink, G., \& Kelsey, J. (2019). Poverty, seasonal scarcity and exchange asymmetries. National Bureau of Economic Research working paper 26357. www.nber.org/papers/w26357.

Frederick, S., Novemsky, N., Wang, J., Dhar, R., \& Nowlis, S. (2009). Opportunity cost neglect. Journal of Consumer Research, 36(4), 553-561. https://doi.org/10.1086/599764.

Gabaix, X. (2019). Behavioral inattention. In D. Bernheim, S. DellaVigna, \& D. Liabson (Eds.), Handbook of behavioral economics (Vol. 2, pp. 261-343). Amsterdam: Elsevier B.V. https://doi. org/10.1016/bs.hesbe.2018.11.001.

Gennetian, L. A., \& Shafir, E. (2015). The persistence of poverty in the context of financial instability: A behavioral perspective. Journal of Policy Analysis and Management, 34(4), 904-936. https://doi. org/10.1002/pam.

Graves, V. (2015). Does poverty really impede cognitive function? Experimental evidence from Tanzanian fishers (master's thesis). University of San Francisco. https://repository.usfca.edu/thes/ 129.

Guiso, L., \& Paiella, M. (2008). Risk aversion, wealth, and background risk. Journal of the European Economic Association, 6(6), 1109-1150. https://doi.org/10.1162/JEEA.2008.6.6.1109.

Hagenaars, A., \& de Vos, K. (1988). The definition and measurement of poverty. The Journal of Human Resources, 23(2), 211. https://doi.org/10.2307/145776.

Haisley, E., Mostafa, R., \& Loewenstein, G. (2008). Myopic risk-seeking: The impact of narrow decision bracketing on lottery play. Journal of Risk and Uncertainty, 37(1), 57-75. https://doi.org/10.1007/ s11166-008-9041-1.

Hamilton, R. W., Mittal, C., Shah, A. K., Thompson, D. V., \& Griskevicius, V. (2019a). How financial constraints influence consumer behavior: An integrative framework. Journal of Consumer Psychology, 29(2), 285-305. https://doi.org/10.1002/jcpy.1074.

Hamilton, R. W., Thompson, D., Bone, S., Chaplin, L. N., Griskevicius, V., Goldsmith, K., et al. (2019b). The effects of scarcity on consumer decision journeys. Journal of the Academy of Marketing Science, 47(3), 532-550. https://doi.org/10.1007/s11747-018-0604-7.

Haushofer, J., \& Fehr, E. (2014). On the psychology of poverty. Science, 344(6186), 862-867. https://doi. org/10.1126/science.1232491.

Hernanz, V., Malherbet, F., \& Pellizzari, M. (2004). Take-up of welfare benefits in OECD countries: A review of the evidence. OECD Social, Employment and Migration working Paper 17.

Huijsmans, I., Ma, I., Micheli, L., Civai, C., Stallen, M., Sanfey, G., \& A. . (2019). A scarcity mindset alters neural processing underlying consumer decision making. Proceedings of the National Academy of Sciences. https://doi.org/10.1073/pnas.1818572116.

Johar, G., Meng, R., \& Wilcox, K. (2015). Thinking about financial deprivation: Rumination and decision making among the poor. Advances in Consumer Research, 43, 208-211. http://acrwebsite.org/ volumes/1020157/volumes/v43/NA-43.

Joy, E. E. (2017). For the poor, does attentional bias or worry explain the relationship between financial stressors and poor cognitive performance? (master's thesis). Washburn University. https://wuir. washburn.edu/handle/10425/409.

Kahneman, D. (2011). Thinking, fast and slow. New York: Penguin Books.

Kahneman, D., \& Frederick, S. (2002). Representativeness revisited: Attribute substitution in intuitive judgment. In T. Gilovich, D. Griffin, \& D. Kahneman (Eds.), Heuristics and biases: The psychology of intuitive judgment. New York: Cambridge University Press.

Kahneman, D., Knetsch, J. L., \& Thaler, R. H. (1991). Anomalies: The endowment effect, loss aversion, and status quo bias. Journal of Economic Perspectives, 5(1), 193-206. https://doi.org/10.1257/jep.5. 1.193.

Kahneman, D., \& Tversky, A. (1979). Prospect theory: An analysis of decision under risk. Econometrica, 47(2), 263-292. https://doi.org/10.1111/j.1536-7150.2011.00774.x.

Kaur, S., Mullainathan, S., Schilbach, F., \& Oh, S. (2019). Does financial strain lower worker productivity? Working paper. https://economics.mit.edu/files/16997.

Kerlinger, F. N., \& Lee, H. B. (2000). Foundations of behavioral research (4th ed.). Fort Worth, TX: Harcourt College Publishers.

Kremer, M., Rao, G., \& Schilbach, F. (2019). Behavioral development economics. In B. D. Bernheim, S. DellaVigna, \& D. Laibson (Eds.), Handbook of behavioral economics: Foundations and applications 2 (pp. 345-458). Amsterdam: Elsevier. https://doi.org/10.1016/bs.hesbe.2018.12.002.

Lewis, O. (1998). The culture of poverty. Society, 35(2), 7-9. https://doi.org/10.1007/BF02838122.

Lichand, G., \& Mani, A. (2020). Cognitive droughts. Working paper 341. University of Zurich, Department of Economics. https://doi.org/10.5167/uzh-185364. 
Lusardi, A., \& Mitchell, O. S. (2014). The economic importance of financial literacy: Theory and evidence. Journal of Economic Literature, 52(1), 5-44. https://doi.org/10.1257/jel.52.1.5.

Lusardi, A., Schneider, D. J., \& Tufano, P. (2010). The economic crisis and medical care usage. National Bureau of Economic Research working paper 15843. papers3://publication/uuid/ 788A2DE0-5C60-4B15-9A2B-4E1A24C67427.

Mani, A., Mullainathan, S., Shafir, E., \& Zhao, J. (2013a). Poverty impedes cognitive function. Science, 341(6149), 976-980. https://doi.org/10.1126/science.1238041.

Mani, A., Mullainathan, S., Shafir, E., \& Zhao, J. (2013b). Response to comment on "Poverty impedes cognitive function." Science, 342(6163), 1169-1169. https://doi.org/10.1126/science.1246799.

Mani, A., Mullainathan, S., Shafir, E., \& Zhao, J. (2020). Scarcity and cognitive function around payday: A conceptual and empirical analysis. CSAE Working Paper Series 2020-04.

Mullainathan, S., \& Shafir, E. (2013). Scarcity: Why having too little means so much. New York: Henry Holt and Company.

Ong, Q., Theseira, W., \& Ng, I. Y. H. (2019). Reducing debt improves psychological functioning and changes decision-making in the poor. Proceedings of the National Academy of Sciences. https://doi. org/10.1073/pnas.1810901116.

Plantinga, A. (2014). Decisions under poverty: The effects of scarcity on cognitive mindset and financial decisions (Master's thesis). Tilburg University. http://arno.uvt.nl/show.cgi?fid=135541.

Plantinga, A., Krijnen, J. M. T., Zeelenberg, M., \& Breugelmans, S. M. (2018). Evidence for opportunity cost neglect in the poor. Journal of Behavioral Decision Making, 31(1), 65-73. https://doi.org/10. 1002/bdm.2041.

Radel, R., \& Clement-Guillotin, C. (2012). Evidence of motivational influences in early visual perception: Hunger modulates conscious access. Psychological Science, 23(3), 232-234. https://doi. org/10.1177/0956797611427920.

Schilbach, F., Schofield, H., \& Mullainathan, S. (2016). The psychological lives of the poor. American Economic Review, 106(5), 435-440. https://doi.org/10.1257/aer.p20161101.

Shah, A. K. (2015). Social class and scarcity: Understanding consumers who have less. In M. I. Norton, D. D. Rucker, \& C. Lamberton (Eds.), The Cambridge handbook of consumer psychology (pp. 673-692). Cambridge: Cambridge University Press. https://doi.org/10.1017/CBO9781107706552. 025 .

Shah, A. K., Mullainathan, S., \& Shafir, E. (2012). Some consequences of having too little. Science, 338(6107), 682-685. https://doi.org/10.1126/science.1222426.

Shah, A. K., Mullainathan, S., \& Shafir, E. (2019). An exercise in self-replication: Replicating Shah, Mullainathan, and Shafir (2012). Journal of Economic Psychology, 75, 102127. https://doi.org/10. 1016/j.joep.2018.12.001.

Shah, A. K., Shafir, E., \& Mullainathan, S. (2015). Scarcity frames value. Psychological Science, 26(4), 402-412. https://doi.org/10.1177/0956797614563958.

Shah, A. K., Zhao, J., Mullainathan, S., \& Shafir, E. (2018). Money in the mental lives of the poor. Social Cognition, 36(1), 4-19. https://doi.org/10.1521/soco.2018.36.1.4.

Shapiro, G. K., \& Burchell, B. J. (2012). Measuring financial anxiety. Journal of Neuroscience, Psychology, and Economics, 5(2), 92-103. https://doi.org/10.1037/a0027647.

Sharma, E., \& Alter, A. L. (2012). Financial deprivation prompts consumers to seek scarce goods. Journal of Consumer Research, 39(3), 545-560. https://doi.org/10.1086/664038.

Sheehy-Skeffington, J., \& Rea, J. (2017). How poverty affects people's decision-making processes. York: Joseph Rowntree Foundation.

Shurtleff, S. (2009). Improving savings incentives for the poor. National Center for Policy Analysis. National Center for Policy Analysis. http://www.ncpa.org/pdfs/ba672.pdf

Skiba, P. M., \& Tobacman, J. (2008). Payday loans, uncertainty, and discounting: Explaining patterns of borrowing, repayment, and default. Vanderbilt University Law School working paper 08-33. http:// ssrn.com/abstract=1319751.

Smaldino, P. (2019). Better methods can't make up for mediocre theory. Nature, 575(7781), 9-9. https:// doi.org/10.1038/d41586-019-03350-5.

Spiller, S. A. (2011). Opportunity cost consideration. Journal of Consumer Research, 38(4), 595-610. https://doi.org/10.1086/660045.

The Economist. (2013). The psychology of scarcity: Days late, dollars short. https://www.economist.com/ books-and-arts/2013/08/31/days-late-dollars-short.

Thaler, R. H. (2015). Misbehaving: The making of behavioral economics. New York: WW Norton \& Company. 
Tversky, A., \& Kahneman, D. (1981). The framing of decisions and the psychology of choice. Science, 211(4481), 453-458.

Van Praag, B. M. S., \& Frijters, P. (1999). The measurement of welfare and well-being: The Leyden approach. In E. Diener, D. Kahneman, \& N. Schwarz (Eds.), Well-being: The foundations of hedonic psychology (pp. 413-433). New York: Russell Sage Foundation.

Vieider, F. M., Martinsson, P., Nam, P. K., \& Truong, N. (2019). Risk preferences and development revisited. Theory and Decision, 86(1), 1-21. https://doi.org/10.1007/s11238-018-9674-8.

Wicherts, J. M., \& Zand Scholten, A. (2013). Comment on "Poverty impedes cognitive function." Science, 342(6163), 1169-1169. https://doi.org/10.1126/science.1246680.

World Bank. (2015). World Development Report 2015: Mind, society, and behavior. Washington DC: The World Bank. https://doi.org/10.1596/978-1-4648-0342-0.

World Health Organization. (2011). Systematic review of the link between tobacco and poverty. http:// apps.who.int/iris/bitstream/10665/136001/1/9789241507820_eng.pdf.

Zhao, J., \& Tomm, B. M. (2017). Attentional trade-offs under resource scarcity. In Lecture notes in computer science (Vol. 10285, pp. 78-97). /https://doi.org/10.1007/978-3-319-58625-0_6.

Zhao, J., \& Tomm, B. M. (2018). Psychological responses to scarcity. In Oxford research encyclopedia of psychology (pp. 1-21). Oxford University Press. https://doi.org/10.1093/acrefore/9780190236557. 013.41 .

Publisher's Note Springer Nature remains neutral with regard to jurisdictional claims in published maps and institutional affiliations. 